\title{
LINC LEVEL 3
}

Bell, J., \& Holt, M. (1987). It's your right!. Ottawa: The Human Rights Directorate, Department of the Secretary of State. $95+$ 25 pages. Free.

anti-racism; citizenship; illustrations

In addition to a teacher's guide, this kit about rights of Canadian citizens and immigrants contains eight modules: 1) basic rights and freedoms; 2) employment rights; 3) tenant's rights; 4) age; 5) sexual harassment; 6) equal pay; 7) race, colour and ethnic origin; and 8) disability. The students' manual contains cartoons illustrating case histories followed by a series of questions to motivate oral discussion.

Bowers, B., \& Godfrey, J. (1983). Decisions. and Teacher's edition. $80+111$ pages. Bowers, B. \& Godfrey, J. (1985). Student Book \$7.95; Teacher Book \$7.95. Decisions decisions. and Teacher's edition. Markham, Ont.: Pippin Publishing Ltd. $122=152$ pages. Student Book \$9.95; Teacher Book $\$ 9.95$.

speaking/conversation

Suitable for multi-level classes, the activities in these books are arranged by contextually-based functions of language. Socially appropriate communication, rather than a specific level of linguistic competence, is stressed. Each chapter relates a problem followed by activities based on discussion and selection of solutions. Topics, functions, strategies, and grammar for each chapter are listed in chart form. The teacher's editions explain how to present the functions in each chapter, suggest 3 levels of role play activities, and give topics for pre-composition discussion; some research topics are briefly outlined. 
Bowers, B., \& Godfrey, J. (1992). Words we use. Scarborough, Ontario: Prentice-Hall Canada Inc. 163 pages. Book: \$13.50; Answer key: $\$ 10.00$

vocabulary; ESL literacy; life skills; exercises; pronunciation key; glossary; crossword puzzles; answer key

The eighteen units are based on readings that describe aspects of Canadian life. The activities that follow each unit topic focus on the vocabulary words in the passage. Students practise pronunciation, identify parts of speech and use the vocabulary in natural English sentences. The book contains a variety of communicative and interactive activities to stimulate discussion.

Brand, D., \& Sri Bhaggiyadatta, K. (1986). Rivers have sources, trees have roots: Speaking of racism. Toronto: Cross Cultural Communication Centre. 192 pages. $\$ 12.95$.

anti-racist education; speaking/conversation; teacher reference; illustrations

This book is a collection of oral stories about personal experiences with racism in Canada. These stories cover several topics: 1) the culture of everyday; 2) childhood; 3) work, and 4) continuing to fight. The stories can be used as classroom material to facilitate oral discussion.

Brand, M., Gallaugher, A., \& Langevin, D. (1992). I can do the job very well. Toronto: Toronto Board of Education. 129 pages. $\$ 20.00$.

life skills and community resources; English for work; illustrations; forms; exercises; teacher guide; answer key

The book is divided into 7 units which chronologically reflect stages of the job search process (e.g., self-assessment and job 
assessment, networking and getting started in a job search, barriers to employment, resumes and application forms, interviews). Notes for the ESL instructor include methodological suggestions, description of the format and the philosophy of the book. Supplementary resources and reference materials are listed at the end of the book. Each unit consists of student stories, questions for discussion and activities.

Bryant, M. (1989). Tutor's guidebook for write on: A guide to writing for the workplace. Saint John, N.B.: Laubach Literacy of Canada. \$2.95.

ESL literacy; speaking/conversation; teacher's guide

Designed to develop a student's ability to write clearly and logically in work-related contexts, Write on focuses on teaching thinking, reasoning and organizing skills. In addition to writing memos, letters, descriptions and instructions, the guide includes reading and discussing the mechanics and process of writing. Practice activities are provided on sentences, editing and note taking. The tutor's guidebook outlines procedures for teaching the 11 units in the student's book and suggests follow-up activities. A chart indicating the kinds of practice exercises is included in the appendix.

Burdy, T., Irwin, A., Langrell, D., \& Wiebe, L. (1986). Citizenship. Workbook 1. 62 pages. Workbook 2. 59 pages. Teacher's Notes. 4 pages. Manitoba: Manitoba Department of Education. Level $1 \$ 2.10$; Level $2 \$ 2.15$; Teacher's Notes $\$ 6.00$.

citizenship; ESL literacy; illustrations; maps; teacher's notes

Materials in Level 1 workbook have been simplified for the adult student with limited literacy skills. Large print, simple sentence structure, simple maps and charts and information in small 
sections have been used throughout the materials, along with activities. Topics cover such areas as municipal, provincial and federal governments, how laws are made, how to vote, people and languages, history, privileges and responsibilities. Level 2 includes maps, charts, illustrations, graphs, diagrams and readings on the topics of geography, history, political parties and voting, and other topics covered in Level 1, but in more depth. Accompanying the workbooks is a booklet containing Teacher's Notes.

Butovsky, L. \& Creatore, C. (1993). Laugh your way to better spoken English. Scarborough, Ont.: Prentice-Hall Inc. 96 pages. Book $\$ 18.67$; Audiocassette $\$ 40.00$.

general language study; illustrations; answer key; audio-cassette

The book contains 100 popular jokes and a variety of language activities related to them. The jokes are categorized by theme and within each theme the jokes are grouped in order of difficulty. Cultural notes, along with introductions provide background information. Language activities include pronunciation practice, vocabulary development, speaking skills development through dramatization, interviews and discussions and grammar practice. All jokes and pronunciation exercises are on the audiocassette. An answer key is found at the back of the book.

Coelho, E. (1989). The jigsaw kit, rev. ed. Toronto: Dominie Press, first published by Duplikits (1985). 23 pages (guide + $(24+26+26+30) \times 3$ pages (workbooks). $\$ 39.95$.

speaking/conversation; ESL literacy; illustrations; exercises; teacher's guide

Designed to stimulate a co-operative learning environment, and to accommodate students of different levels of English ability, 
the workbooks in this kit prepare groups of students to engage in information gap and information transfer tasks. First, students work in "expert groups" where each has identical information on specific topics; then, they re-group into "jigsaw groups" of four, each of whom has different information (from each expert group) that must be shared in order to understand the whole situation. Exercises focus on vocabulary building, reading comprehension, and personal responses to the readings. Quizzes for each unit are available in the teacher's guide.

Cunningham, H., \& Kozakiewicz, N. (1992). What do people really say? Vancouver, B.C.: Vancouver Community College Press. 152 pages. $\$ 16.95$.

speaking/conversation; videocassette; exercises

The teacher's guide and student workbook serve as a guide to the videocassette. The video consists of 17 vignettes set in a variety of situations. Each conversation is built around one language function (e.g. complaining, apologizing, giving instructions). The book is divided into 16 units. Each unit includes a description of the situation, a glossary of the speech functions, cultural notes, teaching suggestions, two sets of comprehension questions, and a set of additional questions. Transcripts and answers appear at the end of the book.

Educational Measurement Research Group, University of British Columbia. (1991). Perfecting your second language: Instruction and practice in English usage for college and university entry level students. Vancouver: UBC, Educational Measurement Research Group. 92 pages. $\$ 10.00$.

grammar; answer key; exercises

The booklet deals with eight grammar problems that appear in ESL learners' writing. Rules, examples and practice activities 
are provided in each chapter. Review exercises and additional reading selections for summarizing, along with all answers, are provided. An appendix contains notes on writing correct sentences and answers.

Fournier, P. \& Cunanan, A. (1990). Integration: A multi-skills approach to improving English. Teacher's manual. 72 pages. Montreal: McGraw-Hill. 134 pages. \$18.25.

general language study; illustrations; answer key

Eight units on various themes (animals, advertising, superstitions, etc.) contain pre-reading exercises, extensive reading passages on popular academic topics, vocabulary and comprehension exercises, suggested writing topics, and self-tests. The teacher's manual outlines the purposes of the materials and provides an answer key for exercises.

Fox, J., Woods, H., with Deeble, C. (1980). Telephone gambits: A module for teaching telephone English to second language learners. Hull, Que.: Supply and Services Canada. 47 pages. $\$ 4.95$.

speaking/conversation; life skills; illustrations

This booklet presents and guides students to practice a variety of telephone exchanges: protocol for business, emergency, and long distance telephone calls, as well as for making appointments and reservations, dealing with complications, and interacting during a call. Unique features are a tone chart for greetings and "Function Dial" for practice dialogues.

Freedman, J. (Ed.). (1987). Ontario's story: For learners of English as a second language. Toronto: Ontario Ministry of Citizenship. 21 pages. Free. 
citizenship; ESL literacy; regional; illustrations; answer key

This booklet has 6 two-page stories, collected from "Newcomer News", about the history and development of Ontario. Stories about the Native people, French rule, the Loyalists, the War of 1812 , changes in the government, and economic development, are followed by exercises in sentence completion, reading comprehension, grammar structures, and vocabulary.

Freedman, J. (Ed.). (1989). The Ontario times: Special citizenship issue. Toronto: Ontario Ministry of Citizenship. 8 pages. Free.

ESL literacy; citizenship; regional; newspaper; illustrations

Newspaper articles on citizens' rights and responsibilities focus on Ontario, listing addresses and phone numbers for Human Rights Commission offices and Race Relations Directorates, and recounting stories of community action. Geographical description of other parts of Canada, and historical information about Canada's name, flag, and birthday are also included.

Holunga, S., Paulauskas, S., \& Seright, L. $(1989,1990)$. Ticket to English 5, Textbook 1 and 2, Activity book. $96+95+220$ pages. Guidebooks 1 and 2 and Audiocassettes. $429+473$ pages. Montreal: Les Editions HRW. Textbook $\$ 19.95$ each; Activity book $\$ 10.95$; Guidebook $\$ 54.95$ each; Audiocassettes (3) $\$ 120.95$.

general language study; life skills; grammar; colour illustrations; figures, audiocassetes; tests; glossary; answer key

These student textbooks are organized by theme. The themes include career planning, consumerism, leisure, education, family life, multiculturalism, and the environment. A glossary of terms, a grammar section and reading for pleasure are featured 
in each of the twelve units. The teacher's pedagogical notes have reproductions of student books, transcripts of taped activities, and descriptions of activities with options for weak and strong students. The evaluation guide contains formative and summative tests and student answer sheets, as well as an answer key. Three audiocassettes are included, two for classroom activities and one for tests.

Johnson, M. (1981). Old tales for new readers: Aesop's fables retold. Winnipeg: Clarity Books. 51 pages. $\$ 3.95$

ESL literacy; grammar; illustrations

These 25 fables have been adapted for second language learners. A cloze exercise based on each fable provides the answers for a crossword puzzle following each reading.

Johnson, M. (1987). Proverbs say it best. Winnipeg: Clarity Books. 42 pages. $\$ 3.95$.

ESL literacy; grammar; vocabulary

Common English proverbs and their translations in colloquial English appear in boldface at the top of each page. Their meaning is explained in the context of a short dialogue or situation, and students are then invited to write their own stories, following the framework given. Less common proverbs, and paraphrasings of them, are listed at the back.

Kabis, G. (1987). Think up your own story. Montreal: Centre Educatif et Culturel Inc. 60 pages. $\$ 13.00$.

ESL literacy; speaking/conversation; vocabulary; illustra-tions; glossary; glossary index 
In each of 17 chapters a full-page black and white photograph introduces the topic of a story. A series of questions that stimulate response to the topic, and a list of relevant vocabulary (organized by who, where, when, why, what, and how questions) prompt students to build individual stories about the photo. A glossary defines the vocabulary printed in bold-face throughout. A chart of language functions and verb tenses shows how topics can be integrated.

Keller, E., \& Warner, S. (1979). Gambits 1: Openers. 57 pages. (1976). Gambits 2: Links. 61 pages. (1979). Gambits 3. Responders, closers, and inventory. 58 pages. Ottawa: Supply and Services. Gambits 1, Gambits 2 \$7.00; Gambits $3 \$ 6.00$.

speaking/conversation; vocabulary; illustrations; index; answer key

These three booklets present and practice over 500 phrases strategically useful in opening, maintaining, verifying, adjusting, or closing conversations. Innovative classroom activities are suggested to practice functionally similar phrases, which are grouped and listed in the margin of most pages. Book 1 deals with phrases to attract attention, introduce topics, digress from a topic, provide opinions, and discuss problems. Book 2 considers phrases to expand on topics, evaluate subjects, or make arguments. Book 3 concerns phrases for responding to various kinds of statements and closing conversations. It also provides a detailed index of the words and phrases appearing in the entire series. The selection of phrases was derived from a corpus of English speech data.

Knickerbocker, N., \& Bosch, S. (1990). First Generation. Vancouver, B.C.: Asian Pacific Foundation of Canada. Free.

ESL literacy; teacher reference; photographs 
This book consists of eighteen biographical sketches of immigrants from various ethnic backgrounds in British Columbia.

McLay, V. (1980). Idioms 1. Ottawa: Supply and Services Canada. 87 pages. Book \$6.95; Audiocassette $\$ 4.05$.

speaking/conversation; vocabulary; illustrations; answer key; index; audiotape

One hundred-fifty common idioms are categorized and indexed by functions and themes, such as time expressions, knowing or agreeing, money matters, socializing, winning or losing. These are introduced in the context of short dialogues. Canadian French, Spanish, and non-idiomatic English equivalents appear in the exercises, and English only in the tests.

McLay, V. (1991). Idioms 2. Ottawa: Canada Communications Group. 73 pages. Book \$8.95; Audiocassette $\$ 13.95$.

speaking/conversation; vocabulary; illustrations; answer key; index; audiocassette

The purpose of this book is to introduce students to common idioms and proverbs in spoken English. The book is divided into 14 topics and all idioms arranged accordingly, in the context of short dialogues.

Mendelsohn, D., Laufer, R., \& Seskus, J. (1984). Functioning in English: Communicatively-based units for the teaching of English. Teacher's manual. Agincourt, Ont.: Hodder \& Stoughton, with Dominie Press. $82+47$ pages. Student Book $\$ 10.95$; Teacher's Book \$6.95.

speaking/conversation; illustrations, maps; teacher's guide 
The production of spoken English suitable for specific social situations is the focus of the functionally-organized activities in this book. Learners are given contexts in which to practice requesting and giving information and directions, interrupting, stating preferences, making suggestions and small talk, agreeing and disagreeing, describing, giving opinions, persuading, and developing an idea. Each of the 10 units offers several different learning activities, citing American and Canadian examples. The teacher's manual lists appropriate introductory comments for each unit, as well as methodology notes.

Morgan, B. (1991). Stories from our class. Toronto: St. Stephen's Community House and the Toronto Board of Education. 14 pages.

\section{ESL literacy}

This booklet is a collection of stories written by ESL students. The stories are grouped according to such topics as personal stories of war and biculturalism. Students express their concerns, opinions and reflections.

Naber, V. \& Sévigny, S. (1993). A grammar manual for Canadian ESL students. Vol. A. A grammar workbook. Vol. A. $289+$ 225 pages. Scarborough, Ont.: Prentice-Hall Inc. Manual $\$ 22.67$; Workbook $\$ 16.00$.

grammar; answer key

Each of the thirteen-unit grammar manuals contains a grammar section with short explanations and charts as well as a practice section with sentence completion exercises and open-ended communicative activities. The simple present and simple past tenses with their continuous forms are first presented. Other grammar units cover plurals, adjectives and adverbs and their comparative and superlative forms, pronouns, prepositions and 
modal auxiliaries. The thirteen-unit workbook complements the grammar manual. A simple grammatical explanation is provided at the beginning of each unit followed by completion exercises and open-ended interactive activities.

Pagurek, J., \& Fitzgerald, B. (\& Gagné, A. (Ed.).). (1987, 1988). Alternatives. (1988). More alternatives. (1989). Even more alternatives. Ville LaSalle, Que.: Didier. Access Book \$6.95; Process Book \$3.45; Teacher Guide \$20.00; Audio-cassettes $\$ 40.00$ each.

general language study; speaking/conversation; series; audiocassettes; module lessons with teacher's guide and student books for each theme

The 9 modules at each level are organized by theme, offering activities at two levels of difficulty, covering aural/oral and literate skills. Modules are grouped in 3, any one of which a teacher can select for classroom study before going on to a module in the next group. Themes include: marketing strategies, life-styles, the magic of movies, remarkable people, terralune, designathon, interact, and take a stand. Selfevaluation activities are provided, as well as oral evaluations and end-of-module tests. Objectives follow the Quebec Ministry of Education guidelines for intermediate English. Sections are coded to indicate levels of difficulty, number of participants, and skill groups. Charts in the teacher's guide to each module allocate the time to be spent on each skill group, level of difficulty, objectives, text characteristics, and the guide provides procedural suggestions, answers, evaluation information, and tapescripts.

Phillips, C. (1985). Keeping up with the Joneses: A soap opera for adult ESL students. Toronto: OISE Press. 202 pages. Kit $\$ 42.75$; Teacher's Guide $\$ 21.00$. 
speaking/conversation; audiocassettes

The continuing story of a young couple, their family, work and friends, provides the framework for language learning activities. Taped and transcribed conversations between 2 or 3 people begin each unit and are followed by exercises in story comprehension, grammar or communication, vocabulary, idioms, discussion, and composition. The grammar and communication exercises, vocabulary, and idioms are listed and cross-referenced by unit. There is a suggested five-day plan for using one unit in the classroom.

Pietrusiak Engkent, Lucia, \& Bardy, Karen. Take part: Speaking Canadian English. 2nd edition. Toronto: Prentice-Hall, Canada, Inc. 130 pages. Student book $\$ 13.50$ (net to schools); Instructor's Manual $\$ 22.00$; Audio cassette $\$ 30.00$.

speaking/conversation; index cross-referencing Culture Notes and language.

New activities promote discussion in pairs and groups; units contain a wide variety of dialogues, discussion topics, activities and assignments. Culture Notes talk about Canadian life; Language Notes expand on features of pronunciation, usage and idiom.

Porter, J. (Ed.). (1991). New Canadian voices. Toronto: Wall \& Emerson, Inc. 298 pages. \$23.95.

ESL literacy; speaking/conversation; oral \& written exercises, photographs.

This book is an anthology of texts written by ESL students from various parts of the world. Main topics include adjusting to Canada, family roots, memories, and becoming a Canadian. Each topic is accompanied by exercises to develop oral and 
writing skills, as well as by a set of questions to motivate group discussion.

Rampaul, Y. (1981). Idioms in context. Winnipeg, Manitoba: Y. Rampaul. 30 pages. Workbook $\$ 6.00$; Teacher's guide $\$ 10.00$.

general classroom study; exercises; illustrations; teacher's guide

This workbook of ten lessons is designed to introduce students to common idioms in various everyday contexts. Students are first introduced to four idioms through sentences which place the idioms in context. Students then apply their understanding of the idioms in follow-up fill-in-the blank exercises. The teacher's guide provides suggestions for teaching a lesson, self-tests and translations of the forty-six idioms in the booklet into Chinese, Vietnamese and Russian.

Reaburn, R. (n.d.). They did it in Canada: Stories about people. Vancouver: Vancouver Community College. 62 pages. $\$ 12.50$.

ESL literacy; exercises; black and white illustrations

The ten stories in this workbook focus on past and present Canadians (e.g. Terry Fox, Steve Fonyo, Glenn Gloud, Timothy Eaton). Each story (approximately 2 pages) is accompanied by comprehension questions, vocabulary exercises, sentence combining and completion exercises and guided paragraph writing assignment.

Scane, J., Guy, A., \& Wenstrom, L. (1991). Think, write, share: process writing for adult ESL and basic education students. Toronto: OISE Press. 86 pages. $\$ 15.95$.

ESL literacy; illustrations; bibliography 
In this book students are introduced to processes of writing compositions through a variety of topics. Chapters focus on writing activities such as 1) before you start; 2) prewriting activities; 3) the first draft and conferencing; 4) the final procedures; 5) linking skills: computers and process writing; 6) solving problems, and 7) process writing activities that work.

Sivell, J. (1991). From near and far. Virgil, Ont.: Full Blast Productions. 116 pages. $\$ 14.95$.

ESL literacy; vocabulary; exercises; teacher guide; answer key The book is a collection of readings and activities organized into four units, each with four stories set in different cultural and geographical contexts around the world. The stories in each unit are thematically linked, progressing in difficulty. Each story has an opening jig-saw reading activity, comprehension questions on the story and on the unit as a whole, textual and interpretative questions, and vocabulary, puzzles and activities. Instructions for all exercises and solutions to the unit puzzles are located at the end of the book. Appended to the book is an introduction to the teacher, offering suggestions on how to adapt the stories and activities and describing the theoretical foundation of the book.

Sutton, M., \& Jones, C. (1984). Read Canada!: Intermediate. 59 pages. Sutton, M. (1985). Read Canada!: Intermediate plus. 87 pages. Hull, Que.: Supply and Services Canada. Intermediate $\$ 6.25$; Intermediate Plus $\$ 7.00$.

ESL literacy; citizenship; illustrations; charts; graphs; answer key

Passages on Canadian history, events, people, resources, literature, inventions, geography, and immigration, among others, are framed by pre-reading questions and follow-up questions, reading comprehension questions, and suggestions for further activities. Skimming, scanning, comprehension, and 
critical reading skills are emphasized. Photos, drawings, charts, graphs, and maps provide visual support for the written texts.

Tappay, R., \& Weber, K. (1985). Math counts, 190 pages. \& (1986). More math counts, 187 pages. Toronto: Globe/Modern Curriculum Press. $\$ 9.45$.

life skills; illustrations; answer key; chart; index

The 80 two-page units on math skills in these two books each begin with a cartoon to illustrate the focus of the lesson, then include exercises to put the math problem into a real-life context. Each unit in the first book ends with a list of jobs that rely on the type of math skill practiced. Each unit in the second book ends with a list of tasks at home and on the job that require the particular math skill. Both books have a section on calculator basics and a review.

Teophil, V. (1983). Idiomatic English, rev. ed. Montreal: Centre Educatif et Culturel Inc. 113 pages. $\$ 12.75$.

speaking/conversation; vocabulary; illustrations; index

Idioms are introduced in the context of comic strips. The 47 chapters focus on different situations; related idioms are grouped and explained, and include notes on grammatical structures. Comprehension exercises follow, featuring discussion questions, sentence completions, and ideas for projects and assignments. The last chapter reviews idioms using "make", "do", "get", "have", and "take", introducing new meanings and crossreferencing expressions that had been introduced in previous lessons.

Toronto Board of Education. (1991). The healthy eating kit. Toronto: Toronto Board of Education. 115 pages. $\$ 15.00$. 
Life skills; exercises; visuals; teacher's notes

The kit is divided into two sections. The first deals with six content areas concerning the importance of eating healthy and the foods necessary to become and stay healthy. Visuals, factual information for the instructor, suggested activities for classroom use and worksheets are included. The second section contains lesson plans, requiring learners to use the information covered in the first section. Activities, classroom worksheets, teacher's notes and background material are also provided.

Toronto Board of Education. (1987). Past...present... future...: A collection of writings by adults learning English as a second language. Toronto: Toronto Board of Education. 37 pages. $\$ 12.00$.

life skills; ESL literacy; regional; illustrations

Adult students of Spanish heritage wrote stories about their lives before coming to Canada and at the present time, and about their hopes for the future. Various levels of English proficiency are represented in the writing. Discussion questions follow almost all of the stories; language- and skill-related questions are also included. 